\title{
Embarking on discovering the mechanisms of resilience: combining language use analysis with neuroscience.
}

German Todorov*1, Karthikeyan Mayilvahanan², Catarina Cunha*1

${ }^{1}$ Emotional Brain Institute Labs, Nathan Kline Institute, Orangeburg, NY, USA

${ }^{2}$ Department of Neurobiology and Behavior, Stony Brook University School of Medicine, Stony Brook, NY, USA

* co-first authors

Correspondence to Nathan Kline Institute, Orangeburg, NY, 10960, USA. email: Catarina.Cunha@nki.rfmh.org

\begin{abstract}
Novel treatments in mental health focus on one's ability to recover and develop resilience. Current concepts are based on The Adaptations Level Theory, which describes the ability of resilient individuals to accustom to new and even downgraded conditions as the new standard, find meaning in trauma, and adapt to new social settings. However, it is not known which treatments specifically help to build up resilience in patients and how to reliably screen for it. Recent studies demonstrated that distinct patterns of language use correlated with various mental health conditions. Utilizing text samples from Holocaust survivors, we compared language use in resilient individuals to people with PTSD and the general population. Holocaust survivors' language use was significantly different from PTSD sufferers, which suggests that we detected a possible resilience word use pattern. Next, we looked into the brain circuitry mechanisms that could be involved in resilience. We found that norepinephrine, the key neurotransmitter in stress response, modulated the activity of amygdala circuitry in a non-linear concentration-dependent manner. The shape and other characteristics of this dependency could be associated with the capacity for resilience.
\end{abstract}

\section{Introduction}

There has been a recent transition in mental health research and treatment policies from a deficit-centered approach to strength-based models that focus on the ability to recover $^{1-4}$. Many of those strength based studies concentrate on resilience ${ }^{5,6}$. Initially, resilience research was undertaken in the field of developmental psychology, focusing 
on children who developed well despite being exposed to stressors over a prolonged time $^{7,8}$. More recently there has been an increased focus on adult resilience in mental health, which is referred to (among many others) as a form of immunity against adversities ${ }^{9}$, the capacity to bounce back ${ }^{10}$ and personal growth ${ }^{11}$. Most concepts are a variation of the Adaptation Level Theory proposed in 1948 by Helson, who hypothesized that resilient individuals accept changed situations as the new norm, even if those entail curbed conditions ${ }^{12}$. For instance, the Cognitive Adaptation Theory described how people find meaning in trauma ${ }^{13}$, and the Interpersonal Adaptation Theory studies showed how individuals adapt to new social settings ${ }^{14}$. There are different hypothesis regarding which factors are important for resilience, from which personal resources such as motivation, positive emotions and social intelligence seem to predominate in recent literature ${ }^{15-19}$. Furthermore, a positive social environment seems to be beneficiary ${ }^{20}$, in which positive parental care was shown to hold the potential to promote lifelong resilience ${ }^{21}$.

There are many attempts in developing treatment strategies that are supposed to induce resilience in people affected by stress and trauma ${ }^{5,6}$, however, which interventions actually help in which cases is not known. One possible way to detect resilience build up would be by studying an individual's language use. Novel research suggests that one can identify people's underlying mental states and motivation by analyzing how words are being used to communicate ${ }^{22-26}$. For instance, research done on texts from poets showed that those who used more first pronouns, but a lower frequency of other-personal references in their poetry had a significantly higher probability to commit suicide than those who used the opposite pattern ${ }^{27}$. Studies in people with PTSD displayed differences in word usage of cognitive words while recalling negative events ${ }^{28}$, which was proposed to be an attempt to gain control over emotions related to traumatic experiences ${ }^{29}$. Linguistic markers in trauma narratives of college students, such as negative emotion and cognition words, predicted their future mental health 22 .

In this study, we examined the linguistic manifestations of resilience in Holocaust survivors compared to text samples from PTSD sufferers and controls. Our results show that language use of Holocaust survivors is different from PTSD sufferers, but close to 
controls. Considering the horrendous extended suffering, trauma and loss Holocaust survivors experienced, this is a remarkable outcome.

Based on this result, we examined mechanisms which may underlie such resilience and hypothesized how they can be leveraged to increase resilience in non-resilient individuals.

There are various individual differences in stress response. Many known hormones, neurotransmitters, neurotrophins, neuropeptides, epigenetic based gene expression modifications, DNA conformation changes (e.g. conformation transitions involving i-motif and G-quadruplex), and transposon activity alterations are implicated in stress response $\mathrm{e}^{30-44}$. The activity and balance of these mechanisms vary significantly between individuals, which contributes to differences in resilience levels. Since resilience requires the incentive and ability to learn new capabilities, we hypothesize that the activation of the circuitry for motivation and learning is involved, which, in turn, requires synapic plasticity and related neuronal and regulatory mechanisms.

The norepinephrine (NE) system would be a fitting candidate for resilience regulation., $\mathrm{NE}$ is a fast-acting neuromodulator implicated in coordinating attentional, emotional and mnemonic mechanisms ${ }^{45,46}$, as well as synaptic strength ${ }^{47-51}$.

Stress induced NE release comes from a brainstem nuclei known as the locus coeruleus (LC). This release results in increased NE stimulation of forebrain areas implicated in emotional behavior, such as the amygdala, the nucleus accumbens, the prefrontal cortex (PFC) and the hippocampus ${ }^{52}$. Chronic hyper responsiveness of the $\mathrm{NE}$ system is associated with anxiety disorders and cardiovascular problems ${ }^{53}$. However, targeting NE receptors in the amygdala can counteract aversive memories in animals and humans ${ }^{54-56}$. We propose that modulation of the NE mechanism could contribute to resilience.

Signaling cascades down-stream of NE receptors are comprised of protein kinase (ERK) and rapamycin (mTOR), which regulate various gene expression mechanisms ${ }^{57-}$ 63 and the synaptic model for memory, including formation of long-term potentiation (LTP) and de-potentiation (LTD) ${ }^{64-67}$. Enforcement of LTP through NE was shown to require DNA methylation and histone acetylation, however, inhibition of histone deactylases (HDACs) did not contribute to further enhancement of NE-induced LTP68. 
Our results confirm previously published studies indicating that higher NE concentration (20 uM) decreases and lower NE concentration (10 uM) increases synaptic transmission in the amygdala, acting via different NE receptors accordingly51,69-72. Additionally, we show that the effect of higher NE concentration (decrease of synaptic transmission) is influenced mostly by GABAA receptors, while the opposite effect of lower NE concentration is partially shaped by GABAB and GABAC receptors. This differentiated concentration dependent circuitry regulation of the amygdala through NE could be a key mechanism for switching from stress response to resilience, and would be consistent with Helson's Adaptation Level Theory.

\section{Results:}

The present study employed a computerized text (sample size was ca. 200-500 words) analysis to examine language usage patterns in female and male Holocaust survivors ( $\mathrm{N}=19$ female, $\mathrm{N}=35$ male), people affected by PTSD years ago $(\mathrm{N}=21)$, and controls, which consisted of data collected from firefighters that went through trauma, but didn't develop PTSD (Control 1, $\mathrm{N}=19$ ), and also general population data (Control 2, $\mathrm{N}=26$ ). We analyzed text samples from Holocaust survivors describing their experiences during WWII, and online posts from forums related and unrelated to PTSD. We detected differences in linguistic markers in texts of similar word count between the Holocaust survivor group and two control groups.

Holocaust survivors display resilient characteristics in language use.

It is known that a high frequency of singular and plural first pronoun usage is an indicator of depression and PTSD 25,73-78. We examined singular first pronoun occurrence in text data from Holocaust survivors, controls and PTSD sufferers, consisting of people who experienced trauma years ago, including childhood trauma. Text from female and male Holocaust survivors showed a low singular first pronoun usage which was comparable to the two control groups, but significantly lower than in texts from PTSD sufferers (Mdiff $=0.1077$, Mdiff $=0.11, p<0.001$, Fig.1a). First person plural pronoun frequency in texts from Holocaust survivors were also similar to both 
control groups, but higher compared to the group PTSD years ago (Mdiff $=0.02103$, Mdiff $=0.01538, p<0.001$, Fig.1b).

Figure 1: Pronoun usage of Holocaust survivors differs significantly from PTSD sufferers. Graph displaying singular and plural first pronoun usage frequency in text samples from Holocaust survivors, PTSD sufferers and controls.

A

Singular 1-st person pronouns

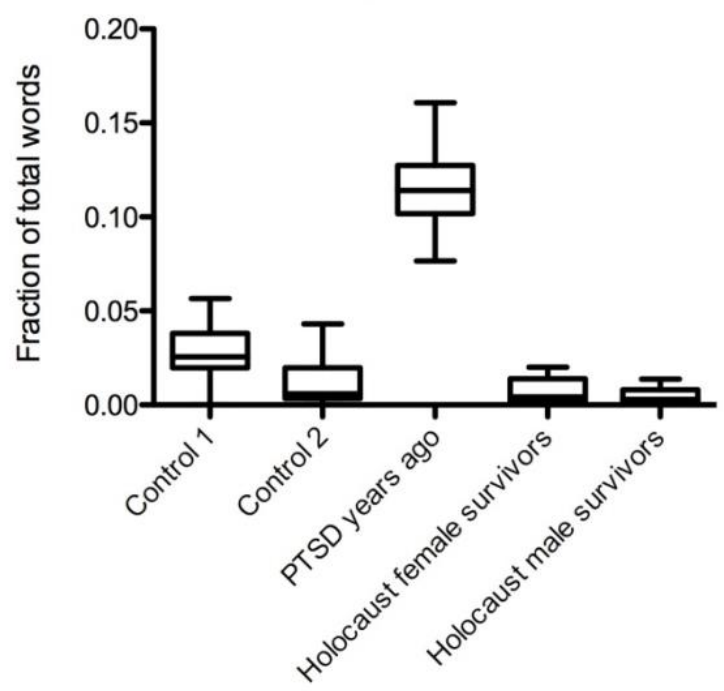

Plural 1-st person pronouns

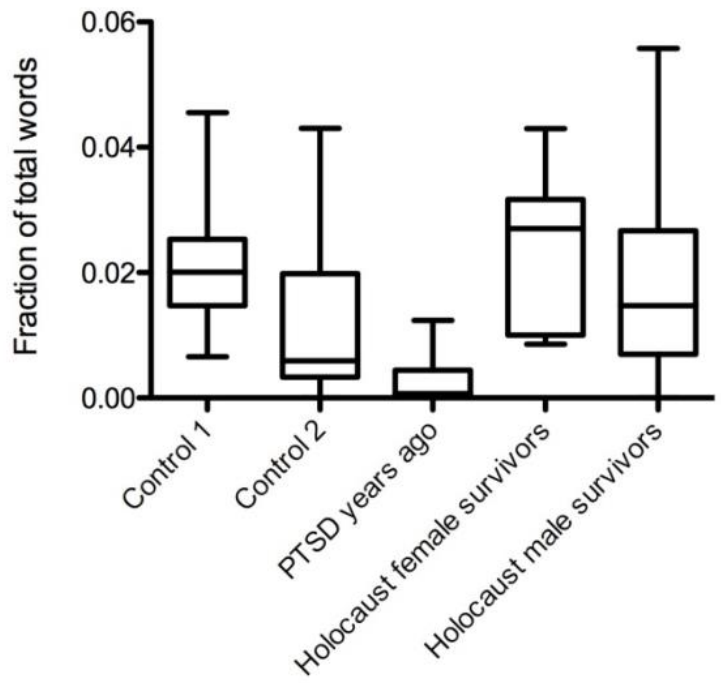

\section{Language use of Holocaust survivor's differences compared to people with PTSD} when screening for negative emotions and cognitive word categories

In female and male Holocaust survivors, word usage of negative emotion words was as low as in both control groups, specially compared to the PTSD group (Mdiff $=0.0139$, Mdiff $=0.01181 p<0.001$, Fig.2a). The usage of cognitive words was lower in both female and male Holocaust survivors compared to the PTSD group and compared to control 2, but not control 1 (Mdiff $=0.04571$, Mdiff $=0.05208$, Mdiff $=0.0385$, Mdiff $=$ 0.04487, $p<0.001$, Fig.2b). 
Figure 2: Holocaust survivors use less negative emotions and cognitive words than PTSD sufferers. Graph displaying occurrence of negative emotion and cognitive word frequencies in text samples from Holocaust survivors, PTSD sufferers and controls.

A

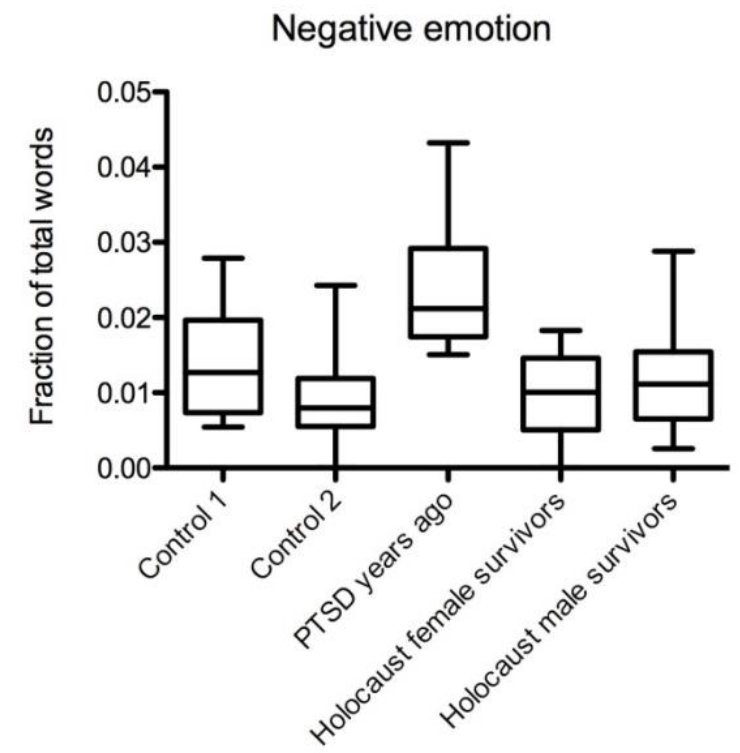

B

Cognitive words

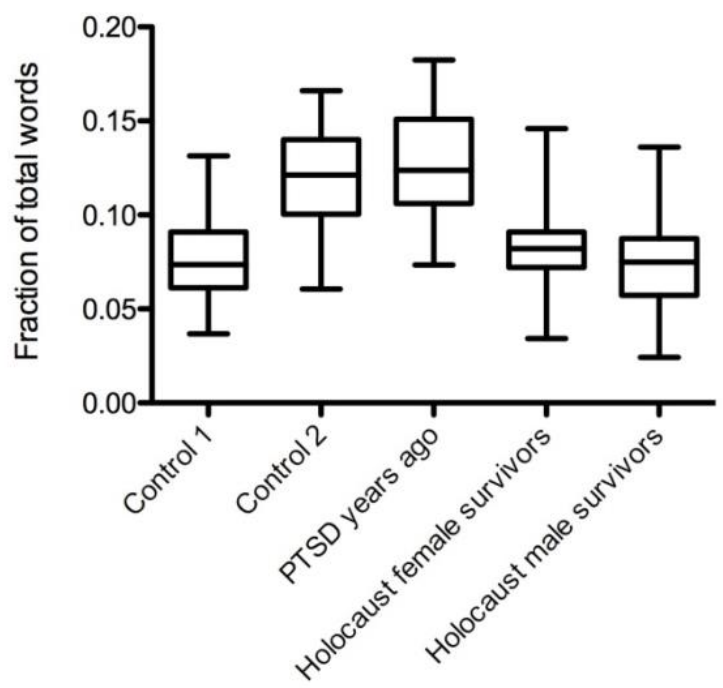

\section{Low depression correlation in language use of Holocaust survivors}

For this part of our study, we screened for a combination of language use patterns that is known to correlate with depression ${ }^{25,27}$. We detected a low correlation of depression in both female and male Holocaust survivor's texts that was comparable to both controls and significantly lower than in PTSD sufferers who experienced trauma years ago (Mdiff $=0.007960$, Mdiff $=0.008448, p<0.001$, Fig.3).

Figure 3: Holocaust survivor's word usage suggests low correlation with depression. Summarized results of depression correlations in text data from Holocaust survivors, PTSD sufferers and controls.

Depression correlation

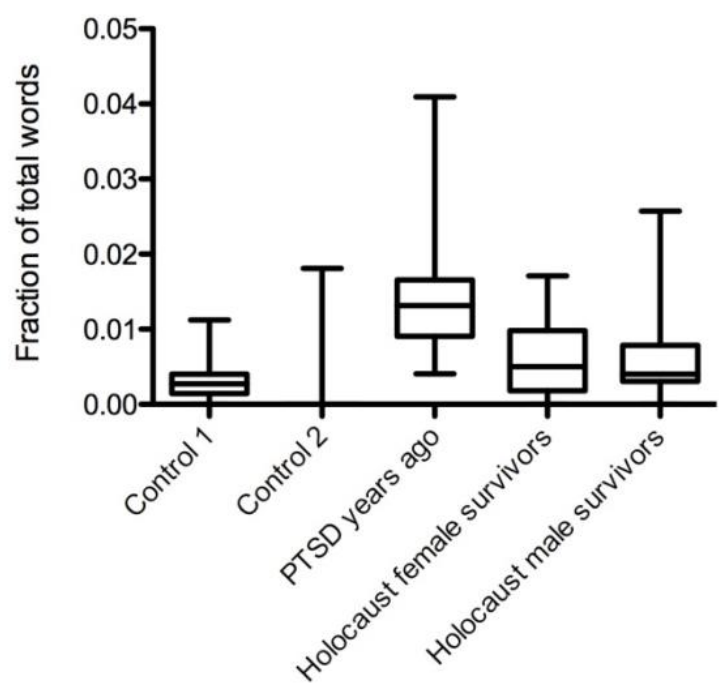


Different NE concentrations have dissimilar effects on principal neurons in the LA and modulate the activity of different inhibitory receptor subtypes

We first evaluated the effect of different NE concentrations on thalamo-LA and corticoLA EPSCs and IPSCs. Synaptic current traces of an LA pyramidal cell under applied NE and control conditions are shown in Figure 5A. An application of $10 \mathrm{uM}$ NE significantly increased synaptic currents of $56.5 \% \pm 9.7 \%(n=13, p V<0.05)$. Application of $20 \mathrm{uM} \mathrm{NE}$ led to a decrease of synaptic currents of $78.2 \% \pm 12.4 \% \quad(n=11, p V<0.05$, example current Fig. 5B). These results are in line with published data ${ }^{51,69-72}$.

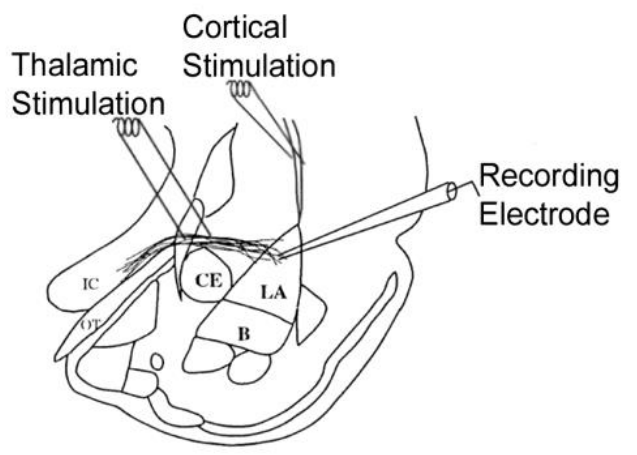

Figure 4: Electrode placement in the internal capsule (thalamic stimulation) and external capsule (cortical stimulation).

Figure 5: A

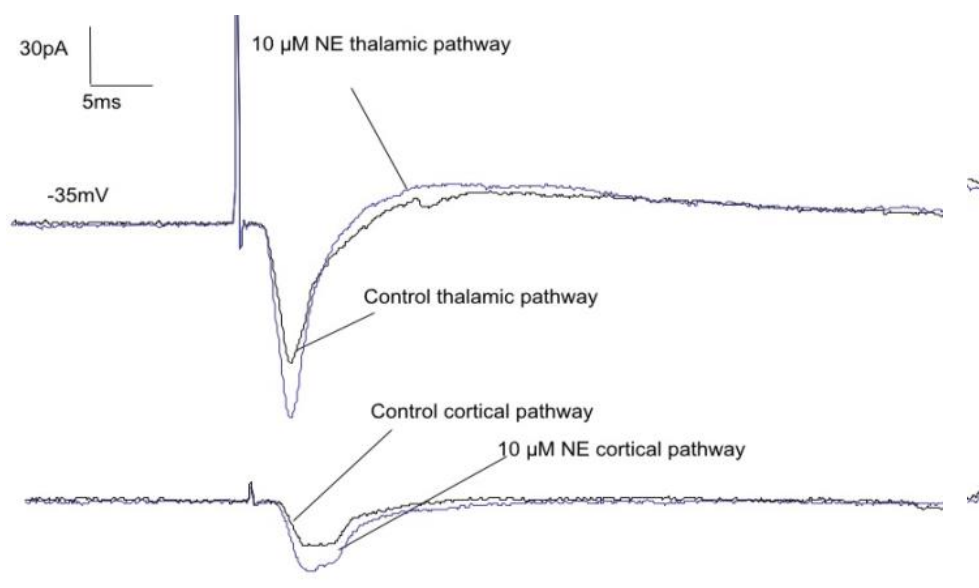

B

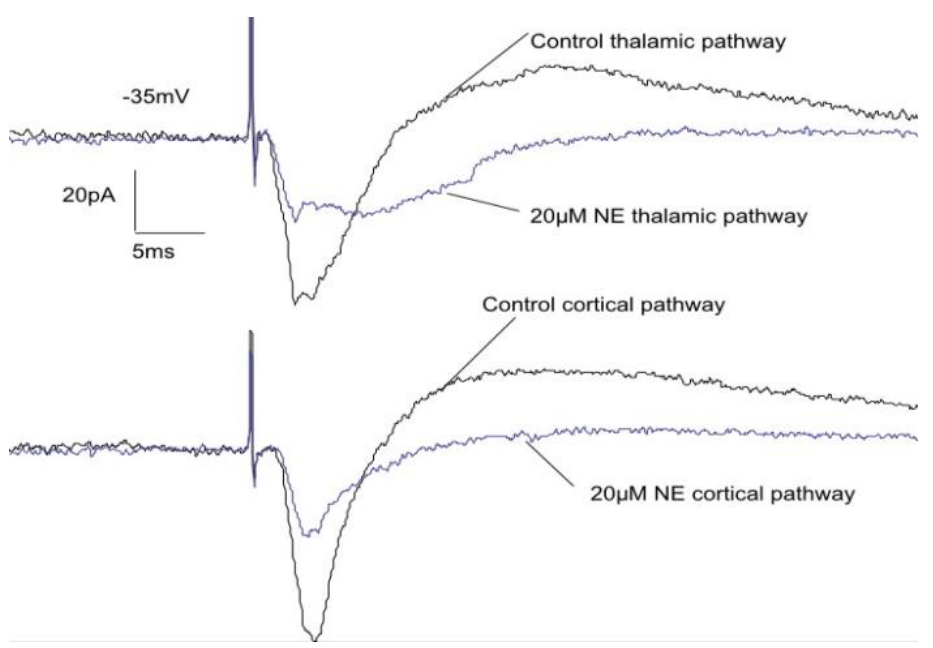

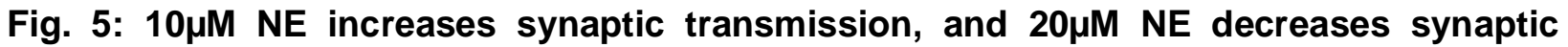
transmission in pyramidal neurons of the lateral amygdala (LA). Whole cell recordings of electrically evoked (thalamic and cortical inputs) synaptic currents of pyramidal neurons of the lateral amygdala, in which $10 \mu \mathrm{M}$ NE increases synaptic transmission, and $20 \mu \mathrm{M}$ NE decreases synaptic transmission at both pathways $(n=24, p<0.05)$. 
GABA is the most frequently used inhibitory neurotransmitter in the mammalian CNS.

There are three different receptor types that mediate inhibitory actions of GABA: The ionotropic GABAA and GABAC receptors, and the metabotropic GABAB receptors. They can be distinguished pharmacologically by their selective responses to various receptor agonists and antagonists ${ }^{79}$.

Table 1:

\begin{tabular}{|l|l|l|}
\hline Drug & Concentration & Effect \\
\hline Muscimol & $1 \mu \mathrm{M}$ & GABAc receptor agonist \\
\hline CGP52432 (CGP) & $5 \mu \mathrm{M}$ & GABAB receptor antagonist \\
\hline Bicuculline & $20 \mu \mathrm{M}$ & GABAA receptor antagonist \\
\hline
\end{tabular}

Bath co-application of $10 \mathrm{UM}$ NE combined with low concentration of $1 \mathrm{uM}$ muscimol, which at this concentration has been shown to act as an GABAC receptor agonist ${ }^{80}$ lead to a decrease of synaptic currents of $18.6 \% \pm 6.3 \%(n=12, p V<0.05$, Fig. $6 A) .10 u M N E$ with the GABAB receptor agonist CGP reduced inhibitory currents by $24.3 \% \pm 6.5 \%$ $(n=12, p V<0.05$, Fig. 6A). Co-application of $10 \mathrm{uM} \mathrm{NE}$ with bicuculline a GABAA receptor blocker didn't affect 10 uM NE modulations further ( $n=12$, Fig. 6A).

When we applied 20 uM NE combined with low muscimol concentrations into the bath, synaptic transmission decreased by $22.4 \% \pm 4.5 \%(n=14, p V<0.05)$, which shows a GABAC receptor influence (Fig. 6B). Co-application of GABAB receptor antagonist CGP with 20 uM NE didn't show any further change in synaptic transmission ( $n=14$, Fig. 6A). The effect of bath application of bicuculline with $20 \mathrm{uM} \mathrm{NE}$ showed an increase in synaptic transmission of $18.6 \% \pm 7.2 \%(n=14, p V<0.05$, Fig. $6 A)$, which suggests a GABAA receptor modulation. 
Figure 6:

A

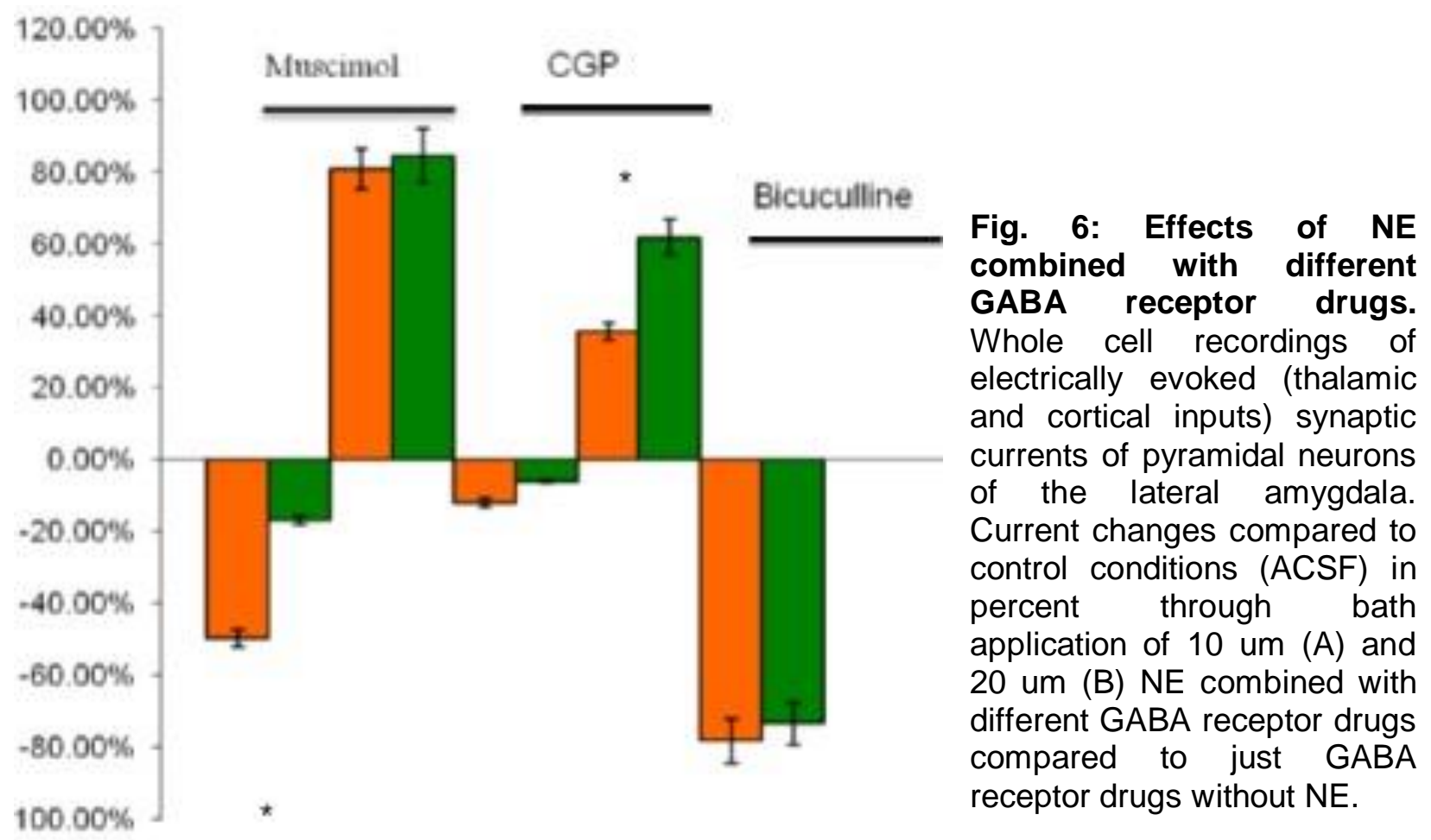

B

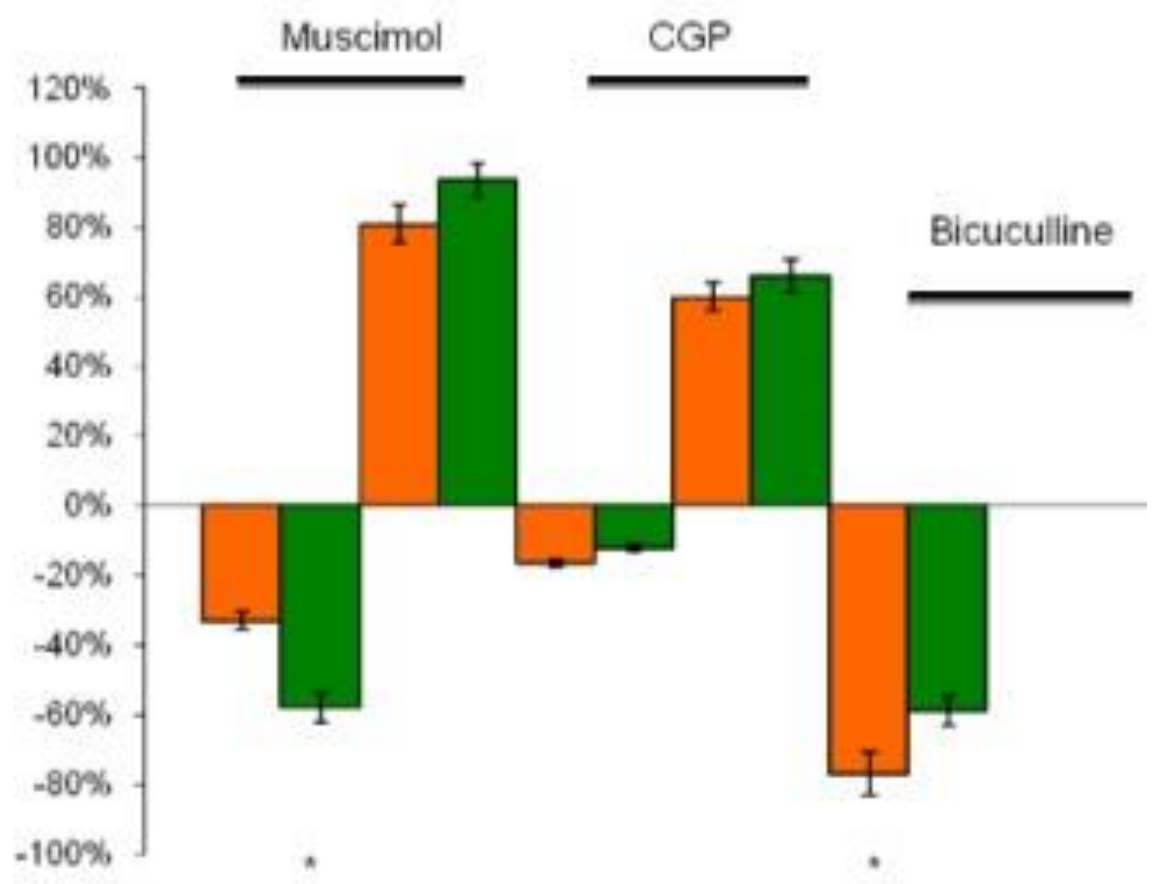




\section{Discussion}

Holocaust survivors display resilient characteristics in language use.

How people use language, specially word category frequencies, is influenced by a variety of factors, including age ${ }^{81}$, gender ${ }^{82}$, and personality ${ }^{83}$. However, for certain word categories, the state of an individual's mental health may have the greatest impact on word usage frequency ${ }^{84}$.

The analysis of our data shows that word usage in female and male Holocaust survivors tends to differ from that of PTSD sufferers, but is very close to controls in a number of word categories, including first and third person pronouns, negative emotion words, and cognitive words.

The most significant difference between Holocaust survivors and PTSD sufferers was detected in the usage of singular first person pronouns. High frequency of singular first pronoun usage is correlated with an increased focus on oneself ${ }^{26,85}$, depression and suicidal tendencies ${ }^{27}$. The low frequency of singular first pronoun use in Holocaust survivors indicates a low probability of PTSD, depression, and suicidal tendencies. However, one has to consider that the cultural and generational differences between the Holocaust survivors and analyzed PTSD sufferers. Culturally, it was less acceptable to focus too much on oneself, however the social integration model is based on data from 1970-90, which should include individuals from that generation ${ }^{86}$. The higher occurrence of plural first person pronouns in text from Holocaust survivors, compared to PTSD sufferers suggests high collaboration with others. This was most likely an important positive factor for survival. Overall, the analysis of pronoun use patterns appears to be instrumental for detecting both the development and prevalence of resilience.

Notably, negative emotion words among Holocaust survivors were lower compared to PTSD sufferers and comparable to controls. This word category is known to strongly correlate with the symptoms of depression ${ }^{22}$. Cognitive word usage was relatively low in Holocaust survivors when compared to PTSD sufferers, but was similar to controls. In previous research, cognitive word usage was reported to be higher in trauma narratives of PTSD sufferers, but not in healthy individuals ${ }^{74}$.

Furthermore, we analyzed the usage of depression-correlated words, a composite category comprising a representative sample of words correlating with depression. We 
found that the usage of depression-correlated words was comparable to controls and lower than PTSD sufferers. Prior research indicates that PTSD comorbidity with depression is common (ca. 50\%) and tends to occur in people with more severe and persistent forms of PTSD ${ }^{87}$. Although Holocaust survivors went through severe and prolonged trauma, overall female and male Holocaust survivors word use shows a low probability for PTSD and depression. Their word pattern usage could be an indicator for resilience. Based on these results we started to examine possible underlying mechanisms of resilience.

Different NE concentrations have dissimilar effects on principal neurons in the LA and modulate the activity of different inhibitory receptor subtypes

Electrophysiological recordings were performed in the LA in response to stimulation of the internal capsule (thalamic stimulation) and external capsule (cortical stimulation), fiber pathways known to carry in Pavlovian threat conditioning the neutral conditioned stimulus (CS), that is paired with a painful shock, the unconditioned stimulus (US) correspondingly ${ }^{88}$. Our whole-cell voltage clamp recordings indicate that high concentrations of 20 uM NE decreased synaptic currents while lower NE concentrations of $10 \mathrm{UM}$ NE increased them.

Co-application of $10 \mathrm{UM} N \mathrm{NE}$ with different GABA receptor drugs showed that it modulated $\mathrm{GABAB}$ and $\mathrm{GABAC}$ receptor mediated currents.

Co-application of 20 uM NE combined with GABA receptor drugs revealed an influence on synaptic transmission through mainly GABAA, but also GABAC receptors. During acute stress and threat responses high NE release was reported in many studies ${ }^{89}$. Therefore, the largest and fastest chloride channel, represented by the GABAA receptor, would have the biggest and more prompt impact on the circuitry. On the other hand, during prolonged stress responses ideally coping mechanisms would kick in, which could be represented by the opposite effect of lower NE concentrations on the LA circuitry combined with participation of smaller and slower GABA receptors (GABAB and $\left(\mathrm{ABAC}\right.$ ) that do not desensitize ${ }^{79}$. Taken together, these effects may represent an important part of the neurobiological mechanism of resilience and appear to be in line with the Helson's Adaptation Level Theory from 1948. 


\section{Future directions and experiments:}

PTSD is believed to be caused by some combination of hyper-conditioning to fear stimuli and impaired fear extinction, leading to excessive and/or maladaptive fearand stress responses in inappropriate situations. Resilience, at least in part, could represent the opposite end [of the normal range] in regard to these traits/responses, i.e. resilience could be characterized by mild hypo-conditioning to fear stimuli and/or mildly enhanced [mildly over-active] fear extinction. While the regulation of fear conditioning and extinction is complex, NE appears to play a major role ${ }^{89-91}$. It is plausible that the sensitivity/responsiveness/connectivity of NE-mediated/modulated pathways involved in fear conditioning and extinction are different in PTSD-prone vs resilient individuals.

The brain structures of particular importance in fear conditioning are locus coeruleus (LC), amygdala [particularly lateral amygdala (LA) but possibly also central amygdala $(\mathrm{CeA})$ ], hippocampus (HPC), medial prefrontal cortex (mPFC) and thalamus, all of which appear to participate in NE-based pathways in some way ${ }^{52}$.

The relevant circuits in these areas may differ between resilient and PTSD-prone [and/or depression-prone] individuals in a number of ways, including:

\section{Intensity and dynamics of NE release in response to external stimuli (during both fear conditioning, stress and extinction training)}

Examples:

LC appears to be responsive to multiple neurotransmitter and hormone based input signals including GABA, $\mathrm{CRH}$, glutamate, serotonin, $\mathrm{NE}$ (presumably via alpha2 AR feedback self-regulatory loop), etc. Sensitivity of LC to these signals may differ between PTSD-prone and resilient individuals and be associated with different amounts and patterns of NE release in response to the same stimulus/situation. 
LC neurons are characterized by phasic firing at rest and tonic firing during stres ${ }^{92-96}$. Firing patterns of LC neurons may differ in PTSD-prone and resilient individuals, e.g. the switch to tonic firing in resilient individuals may occur at higher levels of stress and last for a shorter period of time.

$\mathrm{CeA}$ is reciprocally connected to $\mathrm{LC}$ and appears to be active $\mathrm{LC}$ under stress via $\mathrm{CRH}$ and possibly other inputs, providing a positive feedforward mechanism maintaining high NE output by LC during sustained stress ${ }^{97-100}$. The strength of this connection may differ between PTSD-prone and resilient individuals.

\section{Synaptic inputs to and connectivity between LC, LA, CeA, HPC, mPFC, thalamus}

There is complex connectivity via neuronal projections, dendritic spines, etc between the above structures, providing direct target-specific signaling as well as feedback/feedforward loops and so forth.

For example, projections of NE-ergic LC connect it to amygdala, HPC, mPFC, etc. The number and density of such projections as well as the dendrites/spines on the target neurons may differ between PTSD-prone and resilient individuals.

\section{Neuronal subpopulation ratios in LC, amygdala, HPC, etc} Example:

LC was originally thought to have a homogenous neuronal population but is now believed to consist of functionally distinct subpopulations of neurons ${ }^{101,102}$. Absolute and relative size of these subpopulations may differ between PTSD-prone and resilient individuals. Same is likely to apply to amygdala, and elsewhere.

\section{Absolute receptor density and receptor ratios of post and pre-synaptic receptors in LC, LA, HPC, mPFC, etc neurons (including differential activity of receptor subtypes)}

NE signaling involves multiple receptors, most notably alpha1, alpha2, beta1, beta2, with distinct and sometimes opposing functions (e.g. alpha2 agonists tend to suppress 
NE release and are involved in inhibitory feedback loops), and other receptor families, most notably GABA (GABAA, GABAB, GABAC) modulate NE pathways ${ }^{48,50,51,71,72,89}$. Receptor densities (absolute and relative), subtype ratios, etc may differ between PTSD-prone and resilient individuals.

Sensitivity/responsiveness of intracellular neuronal signaling pathways modulating LTP/LTD/synaptic scaling (i.e. long-term circuitry changes) in response to NE as well as NE-suppressing signals (e.g. GABA)

Development of PTSD or related pathologies is associated with maladaptive neuroplasticity leading to long-term circuitry changes via LTP/LTD/synaptic scaling. Neurotransmitter release (NE release in this case) may be a necessary early step in neuroplasticity but the end result depends on multiple downstream and/or modulating regulatory participants, such as G-proteins, BDNF, TrkB, MAPK, CREB, mTOR, etc $^{103,104}$. The expression/activity of the signal pathway genes/proteins can be up and down-regulated (e.g. via epigenetic modifications) and thus affect the sensitivity of the neuron to NE (or GABA or etc) in regard to the resulting neuroplasticity and long-term circuitry changes. There may be a meaningful difference between PTSD-prone and resilient individuals, e.g. the same level of NE may result in less LTP in resilient individuals.

Example:

NE was shown to enhance LTP in hippocampus, affecting memory formation ${ }^{47,48}$.

Activity of glia in or near LC, LA, HPC, mPFC, etc

Glia, particularly astrocytes, are known to modulate both short-term neuronal activity as well as neuroplasticity. Glia can be directly affected by NE.

Example: Beta AR are expressed in astrocytes, which are known to modules neural signaling ${ }^{105}$.

\section{NE concentration dependencies (weak vs strong conditioning)}

$\mathrm{NE}$ effects in many brain regions are [non-linearly] dependent on NE levels. For example, lower NE levels in PFC were reported to promote cortical function (working 
memory, cognitive flexibility) whereas higher NE levels appear impair prefrontal signaling ${ }^{106-112}$.

NE has been shown to enhance fear conditioning for multi-trial but not single-trial conditioning protocols ${ }^{89}$. It appears that weak conditioning protocols may not rely on NE release (or at least not as significantly) whereas the strong conditioning protocols do. This might be a result of NE concentration differences, i.e. the strong conditioning involving a NE buildup to much higher levels resulting in substantially greater neuroplasticity/circuitry changes [and hence presumably "emotional labeling", etc].

There is some evidence that LTP in HPC is likely sensitive to NE levels and/or efflux rates $^{113}$. It also appears that NE in BLA affects HPC-mPFC plasticity, depending on NE levels ${ }^{114}$.

The shape of the NE effect-vs-concentration dependencies (which may be different for different brain regions), may differ between PTSD-prone and resilient individuals.

Note: The complex non-linear NE effect vs concentration dependencies may be a result of competing effects of different NE receptors, but also other factors, such as NE reaching levels triggering the release of other signaling agents.

\section{NE and memory consolidation}

NE appears to strengthen (enhance consolidation of) contextual representation of fear memories [which was blocked by propranolol, suggesting beta-AR mediated signaling] ${ }^{115,116}$. This is also consistent with the enhancing effect of NE (at high levels) on hippocampal LTP. Taken together this indicates a likely role of NE in "emotional labeling" of memories. "Emotional labeling" of memories may be stronger in PTSDprone individual and weaker in resilient ones. This may reflect differences in beta-AR mediated signaling, e.g. different beta adrenergic receptor densities, receptor recycling or etc. 


\section{NE and fear extinction}

The relationship between NE and fear extinction appears to be complex and depend on NE levels, timing, brain region, etc ${ }^{91,113,117-123}$. NE was shown to facilitate and possibly be critical for contextual fear extinction.

It appears that low levels of NE are required for or facilitate extinction learning whereas high NE levels (associated with high levels of stress) tend to impair it. Giustino and Maren reported that high NE level in BLA strengthens fear memories possible at the expense of extinction memories ${ }^{113}$. This is consistent with known antagonistic effect of stress on fear extinction.

Guistino and Maren (2018) proposed that LC-NE system dynamically regulates fear extinction (cued and contextual) and that net effects depend on prevailing level of stress (and hence NE) at the time of [extinction] learning. They suggested that low LE levels of NE release [from LC] prior to delayed extinction promotes extinction learning whereas high NE levels impair it ${ }^{113}$.

PTSD-prone and resilient individuals may differ in terms of intensity and timing of NE release in response to stressful stimuli. They may also differ in regard to NE levels (in BLA, HCP and etc) at which fear memories override extinction memories and vice versa as well as in regard to other factors influencing competition of fear conditioning vs extinction learning, such as responsiveness to GABA-ergic modulation [which, in turn, may depend, for example, on GABAA/GABAC ratio and so forth]

\section{Epigenetic modifications}

Most of the above mechanisms depend of the levels of expression of a large number of genes. In many if not most cases, that expression is affected by epigenetic mechanisms. In fact, long-term gene expression changes associated with cell differentiation as well as long-term neuronal plasticity/circuitry changes depend on epigenetic mechanisms, particularly DNA methylation and histone modifications. DNA 
methylation changes may be partly heritable. They also occur extensively during development and cell differentiation as a key element in the mechanisms of achieving and maintaining tissues-specific phenotype. In neurons, DNA methylation (as well as other epigenetic changes) can also occur in adult neurons during synaptic plasticity ${ }^{38,124-128}$ and influenced through NE mechanisms ${ }^{53,68,129}$.

It is likely that at least some of the morphological and functional differences in the circuitry between PTSD-prone and resilient individuals are due to the differences in the patterns of epigenetic modifications in neurons and possibly astrocytes in relevant brain regions.

In relation to NE-dependent pathways, epigenetic changes may, for example, be in the genes (or corresponding regulatory sequences) for different adrenergic receptor types, the corresponding G-proteins and so forth. The genes for different types of GABA receptors (which modulate NE pathways) may also be epigenetically modified. Various downstream elements of NE and GABA-ergic signaling [esp. those relevant to long-term plasticity/circuitry changes] are likely to be epigenetically modulated as well -- possibly differently in resilient vs PTSD-prone individuals.

\section{Transposons in combination with epigenetic mechanisms}

Transposable elements (TEs) were thought to be transcriptionally silent junk DNA. However, there is emerging evidence that some TEs are functional elements in mammalian genomes. Notably, the brain is one of the few organs where transposons can be active in all phases of lifespan. TEs frequently interact with the epigenetic mechanisms during development and in response to environmental inputs such as stress. Barbara McClintock, who discovered TEs, proposed that TEs are an integral part of the genomic control apparatus, especially in response to stress. Indeed, stress was shown to increase the activity of TEs in the brain, leading to either adaptive or maladaptive regulatory and structural changes. Recently, a number of mental disorders including Rett syndrome, PTSD, and schizophrenia have been correlated to aberrant TE activity. The more adaptive responses to stress, tend to involve fairly transient increase 
in TE activity that is quickly downregulated via TE suppression mechanisms such as epigenetic modifications ${ }^{41,43,44}$.

We hypothesize that individuals who have a diminished capacity to suppress stressinduced activation of TEs may be at higher risk of developing a variety of dysregulation disorders such as PTSD or type II diabetes. On the other hand, individuals with a more efficient TE suppressing system may be more resilient, especially in regard to the diseases of the CNS where TE activity is especially high.

Another possible way TEs can affect resilience is via heritable TE-induced genome changes. Transposons can be active during early embryogenesis and thus end up in the germline. Another possible but less research pathway of TE insertion into germline is during spermatogenesis or late oogenesis. These mechanisms of heritable TEinduced genomic rearrangements are also likely to be activated or intensified by stress and may contribute to trans-generational changes in disease risk and resilience.

\section{Searching for resilience in humans using saliva samples:}

Resilient individuals could be detected in a highly traumatized family showing mental health scores comparable to individuals from non-traumatized families. There could be a number of underlying mechanisms leading to resilience, such as:

1. They have a very low adaptation rate to the environment, so their organism ignores most environmental information input. In the case of psychological trauma, this could be adaptive. However, in the case of other selective pressures, such as physical stressors, this could be maladaptive and increase the likelihood of negative outcomes.

2. They are able to fully and quickly adapt to stressors (and psychological stressors in particular) making stress response relatively brief and self-limiting, such that the longer-term consequences of stress (epigenetic changes and TE-induced genomic rearrangements) are minimal.

In the first case, the TEs/methylation/gene expression levels would be comparable to those in the individuals from families with low trauma occurrence. In the second case, the resilient individuals would differ in the TEs/methylations/gene expression levels from 
non-resilient family members and also from individuals from the families with low trauma occurrence.

\section{Proposal of experiments to test our hypothesis on human saliva samples over generations:}

Transposons (TE) are known to be up-regulated and more active during stress. They also occur highly in telomeres ${ }^{38}$, which are known to be shortened or otherwise affected by stress ${ }^{39}$. Most of the time and in most tissues, TE activity is suppressed, primarily through DNA methylation (DNMT3 enzymes in particular are involved). MicroRNAs also appear to have a role in TE regulation ${ }^{38}$.

Our suggestion is to screen for TEs by using next-generation DNA sequencing searching for polymorphic mobile element insertions (pMEls) or even detecting de novo MEls in saliva from humans. Different methods have been developed for the identification of MEls using high-throughput sequencing. MEls can be analyzed directly from whole-genome sequencing data.

\section{Data analysis:}

In deep sequencing, the goal is to detect polymorphic or de novo MEls by a computational analysis. Different algorithms have been developed to find MEIs, and two are the principal strategies to do it: "paired-end-reads mapping" and "split-read mapping".

\section{To summarize:}

Correlation of TEs with methylation levels specially of DNMT3s and telomere length would make a strong case for stress vs resilience as adaptation mechanism detection in families that were highly exposed to trauma vs families of low trauma exposure. One would also need to screen for microRNAs at some point. In the end one would combine this data with mental health scores from individuals from at least 2, but ideally 3 generations. Differences in TE activity, methylation and gene expression patterns would bring us closer to detect how adaptation is being transferred from one generation to the other. One should point out that adaptation doesn't necessarily mean that a good 
outcome (in our eyes) will be generated at first. Only by observing more generations over time one would be able to dissect out which adaptations are positive vs negative.

\section{Methods}

\section{Data collection and categorization}

Text data for the Holocaust survivor's groups was collected from public available data from foundations. For the PTSD group we collected text samples from public forums collected and screened according to previously described procedures ${ }^{130}$. Many forum users describe their diagnosis in a large variety of mental health conditions ${ }^{131}$. In this study we focused on resilience. A human editor assessed each description and diagnosis and removed quotes, or other disingenuous text sections. To ensure that each included forum user has a sufficient amount of data, we ensured that each individual had at least 150 words.

In order to have age- and gender-matches in our groups we analyzed each text sample and its language as described in previous published studies ${ }^{132}$.

A large number of possibly suitable text samples were manually screened and either discarded or sorted into the groups of interest based on the content of the excerpt itself, forum thread context and other available anonymous information. Our first control group consists of data from firefighter forums, where users discuss work, daily life and extreme/traumatic situations, but, however, are not PTSD sufferers. Our second control group consists of general population data.

\section{Analysis}

We used word usage frequency analysis conceptually similar to that in LIWC methodology and program ${ }^{26}$. LIWC was shown to be effective in detecting a number of psychologically salient language usage patterns. We developed a custom software program that extended LIWC approach by combining it with character language models 
(CLMs) for additional word matching features as well as additional and/or modified word categories tailored to PTSD. This provided a score even for very short texts ${ }^{133}$. Word matching included pattern matching whole words, roots, salient word parts, simple stemming, split verb/expression stemming and others.

Based on literature 22,27,76,81,84,134-140 and text screening, the following word categories were determined to be potentially salient for PTSD and depression were used in this study:

- Singular first-person pronouns (related to self only)

- Plural first-person pronouns (related to group including self)

- Negative emotions

- Cognitive words

- Words positively correlated with depression $25-27,134,141,142$

For each word category and population group, a standard set of usage frequency statistical data was calculated (using stats and stats-lite $\mathrm{npm}$ software modules), including mean, median, variance, standard deviation, and percentile distribution. Statistical significance of group differences was calculated using t-test, ANOVA, and post hoc Tukey test. For each user, we scored each text based on the character $n$ grams in the text with the CLMs for the condition. This method followed previous work on predicting mental health in social media ${ }^{130}$.

This study is an analysis of existing, de-identified and publicly available data. No sensitive information was collected, and the study DATA is completely anonymous. As by regulation of $\S 46.104$, if the project does not include any interaction or intervention with human subjects or include any access to identifiable private information, then the project does not require IRB review and is exempt.

\section{Electrophysiological Experiments}

Slice preparations

The amygdala slice preparation has been described previously ${ }^{143}$. Rats were anesthetized with subcutaneous injection of ketamine (100 mg/kg body weight) and thiazine hydrochloride $(1 \mathrm{mg} / \mathrm{kg}$ ). To obtain acute slices of the LA for recording, the rats 
were deeply anesthetized with a subcutaneous injection of ketamine $(100 \mathrm{mg} / \mathrm{kg}$ body weight) and thiazine hydrochloride (1 $\mathrm{mg} / \mathrm{kg})$. After transcardial perfusion with ice-cold artificial cerebro-spinal fluid (ACSF) containing (in mM), $\mathrm{NaCl} 124, \mathrm{KCl} 5$, NaH2PO4 $1.25, \mathrm{NaHCO}_{2} 26, \mathrm{MgSO} 42, \mathrm{CaCl} 22$, glucose 10 , that was continuously gassed with $5 \% \mathrm{CO} 2 / 95 \% \mathrm{O} 2$, the brain was removed and cut into $300 \mu \mathrm{m}$ thick sagittal slices on a vibratome in ice cold ACFS. To allow recovery, slices were incubated for $1 \mathrm{~h}$ in ACSF at a temperature of $36^{\circ} \mathrm{C}$. For recording, the slices were transferred into a submerged type recording chamber where they were continuously superfused at $3 \mathrm{ml} / \mathrm{min}$ with ACSF at room temperature.

\section{Electrophysiology}

For whole-cell recordings, slices were transferred to a submersion-type recording chamber where they were continuously perfused with oxygenated ACSF at a rate of 4 $\mathrm{ml} / \mathrm{min}$. Whole-cell recordings were obtained from the pyramidal cells in the LA region. Patch electrodes were fabricated from borosilicate glass and had a resistance of 5.08.0 M $\Omega$. The pipettes were filled with internal solution composed of (in $\mathrm{mM}$ ): potassium gluconate, 130; sodium gluconate, 2; HEPES, 20; MgCl2, 4; Na2ATP, 4; NaGTP, 0.4; EGTA, 0.5. In order to block sodium spikes, $5 \mathrm{mM}$ QX 314 (Sigma-Aldrich) was added, as was $0.5 \%$ biocytin for morphological single cell reconstruction. Neurons were visualized with an upright microscope (Nikon Eclipse E600fn) using the Nomarski-type differential interference optics through a $60 \times$ water immersion objective. Neurons with a pyramidal appearance were selected for recordings. Neurons were voltage clamped using an Axopatch 200B amplifier (Axon Instruments, Foster City, CA, USA). Excitatory (EPSCs) and inhibitory postsynaptic currents (IPSCs) were recorded at a holding potential of $-35 \mathrm{mV}$. Synaptic responses were evoked with sharpened tungsten bipolar stimulating electrodes (2 mm diameter, World Precision Instruments, Sarasota, FL, USA) placed in the cortical and thalamic pathway, 50-100 $\mathrm{mm}$ from the recording electrode. Stimulation was applied, at $0.1 \mathrm{~Hz}$, using a photoelectric stimulus isolation unit having a constant current output (PSIU6, Grass Instrument Co., West Warwick, RI, USA). Access resistance (8-26 M 2 ) was regularly monitored during recordings, and cells were rejected if it changed by more than $15 \%$ during the experiment. The signals 
were filtered at $2 \mathrm{kHz}$, digitized (Digidata 1440A, Axon Instruments, Inc.), and stored on a computer using the pCLAMP10.2 software (Axon Instruments, Inc.). The peak amplitude, $10-90 \%$ rise time, and the decay time constant of IPSCs were analyzed offline using pCLAMP10.2 software (Axon Instruments).

\section{Drugs}

All pharmacologically active substances were bath applied for $10 \mathrm{~min}$ to achieve stable responses before their effects were tested. We used $0.1 \mu \mathrm{M}$ muscimol (C5-aminomethyl acid; Sigma) as GABACR agonist. To make sure that the evoked responses were not GABAAR-mediated $20 \mu \mathrm{M}$ bicuculline (GABAAR antagonist; Sigma) was co-applied. As GABABR agonist we applied $50 \mu \mathrm{M}$ CGP52432 (Tocris).

\section{Histochemistry}

After each recording session, slices were immersion fixed in $4 \%$ paraformaldehyde in $0.1 \mathrm{M}$ phosphate buffer, $\mathrm{pH} 7.4$, at $4^{\circ} \mathrm{C}$ for $24 \mathrm{~h}$. The slices were processed using standard histochemical techniques for visualization of biocytin with 3,3diaminobenzidine (Sigma-Aldrich). For documentation, stained cells were photographed using a digital camera attached to a standard laboratory microscope.

\section{Author contributions statement}

Catarina Cunha and German Todorov conceived of the presented idea. German Todorov developed and performed the computations. Catarina Cunha designed and performed whole cell recordings, histochemistry and verified the analytical methods. All authors discussed the results and contributed to the final manuscript.

\section{Competing interests}

All author declare that they have no significant competing financial, professional, or personal interests that might have influenced the performance or presentation of the work described in this manuscript. 


\section{Data availability statement}

The data that support the findings of this study are available from the corresponding author (C.C.), upon reasonable request.

1 Kleinman, A. Rebalancing academic psychiatry: why it needs to happen - and soon. $\mathrm{Br} J$ Psychiatry 201, 421-422, doi:10.1192/bjp.bp.112.118695 (2012).

2 Rashid, T. \& Ostermann, R. F. Strength-based assessment in clinical practice. J Clin Psychol 65, 488-498, doi:10.1002/jclp.20595 (2009).

3 Trepper, T. S. et al. Solution focused therapy treatment manual for working with individuals research committee of the solution focused brief therapy association. Retrieved July 23, 2008 (2008).

4 Priebe, S., Omer, S., Giacco, D. \& Slade, M. Resource-oriented therapeutic models in psychiatry: conceptual review. British Journal of Psychiatry 204, 256-261, doi:10.1192/bjp.bp.113.135038 (2014).

5 Bonanno, G. A., Romero, S. A. \& Klein, S. I. The Temporal Elements of Psychological Resilience: An Integrative Framework for the Study of Individuals, Families, and Communities. Psychological Inquiry 26, 139-169, doi:10.1080/1047840X.2015.992677 (2015).

6 Thomas, S. et al. Promoting Mental Health and Preventing Mental Illness in General Practice. London journal of primary care 8, 3-9, doi:10.1080/17571472.2015.1135659 (2016).

7 Anthony, E. J. \& Cohler, B. J. The Invulnerable Child. (Guilford Publications, 1987).

8 Garmezy, N., Masten, A. S. \& Tellegen, A. The study of stress and competence in children: a building block for developmental psychopathology. Child Dev 55, 97-111 (1984).

$9 \quad$ Kalisch, R., Muller, M. B. \& Tuscher, O. A conceptual framework for the neurobiological study of resilience. Behav Brain Sci 38, e92, doi:10.1017/S0140525X1400082X (2015).

10 Tusaie, K. \& Dyer, J. Resilience: a historical review of the construct. Holist Nurs Pract 18, 3-8; quiz 9-10 (2004).

11 Onken, S. J., Craig, C. M., Ridgway, P., Ralph, R. O. \& Cook, J. A. An analysis of the definitions and elements of recovery: a review of the literature. Psychiatr Rehabil J 31, 9-22 (2007).

12 Helson, H. Adaptation-level as a basis for a quantitative theory of frames of reference. Psychological Review 55, 297-313, doi:10.1037/h0056721 (1948).

13 Taylor, S. E. Adjustment to threatening events: A theory of cognitive adaptation. American Psychologist 38, 1161-1173, doi:10.1037/0003-066X.38.11.1161 (1983).

14 Burgoon, J. K., Stern, L. A. \& Dillman, L. Interpersonal Adaptation: Dyadic Interaction Patterns. (Cambridge University Press, 2007).

15 Amering, M. \& Schmolke, M. Recovery in Mental Health: Reshaping scientific and clinical responsibilities. (Wiley, 2009). 
16 Gloria, C. T. \& Steinhardt, M. A. Relationships Among Positive Emotions, Coping, Resilience and Mental Health. Stress Health 32, 145-156, doi:10.1002/smi.2589 (2016).

17 Moore, P. J. et al. Psychological resilience: the impact of affectivity and coping on state anxiety and positive emotions during and after the Washington, DC sniper killings. Anxiety Stress Coping 27, 138-155, doi:10.1080/10615806.2013.828202 (2014).

18 Tugade, M. M., Fredrickson, B. L. \& Barrett, L. F. Psychological resilience and positive emotional granularity: examining the benefits of positive emotions on coping and health. J Pers 72, 1161-1190, doi:10.1111/j.1467-6494.2004.00294.x (2004).

19 Friborg, O., Barlaug, D., Martinussen, M., Rosenvinge, J. H. \& Hjemdal, O. Resilience in relation to personality and intelligence. International Journal of Methods in Psychiatric Research 14, 29-42, doi:10.1002/mpr.15 (2006).

20 Helgeson, V. S. \& Lopez, L. in Handbook of adult resilience. 309-330 (Guilford Press, 2010).

21 Champagne, F. A. Epigenetic mechanisms and the transgenerational effects of maternal care. Frontiers in Neuroendocrinology 29, 386-397, doi:https://doi.org/10.1016/j.yfrne.2008.03.003 (2008).

22 Pennebaker, J. W. Dealing with a traumatic experience immediately after it occurs. Adv Mind Body Med 17, 160-162, doi:10.1054/ambm.2000.0307 (2001).

23 Baikie, K. A., Geerligs, L. \& Wilhelm, K. Expressive writing and positive writing for participants with mood disorders: an online randomized controlled trial. J Affect Disord 136, 310-319, doi:10.1016/j.jad.2011.11.032 (2012).

24 Pennebaker, J. W. \& Lay, T. C. Language use and personality during crises: Analyses of Mayor Rudolph Giuliani's press conferences. Journal of Research in Personality 36, 271282, doi:10.1006/jrpe.2002.2349 (2002).

25 Rude, S., Gortner, E.-M. \& Pennebaker, J. Language use of depressed and depressionvulnerable college students. Cognition and Emotion 18, 1121-1133, doi:10.1080/02699930441000030 (2004).

26 Pennebaker, J. W., Mehl, M. R. \& Niederhoffer, K. G. Psychological aspects of natural language. use: our words, our selves. Annu Rev Psychol 54, 547-577, doi:10.1146/annurev.psych.54.101601.145041 (2003).

27 Stirman, S. W. \& Pennebaker, J. W. Word use in the poetry of suicidal and nonsuicidal poets. Psychosom Med 63, 517-522 (2001).

28 Boals, A. \& Klein, K. Word Use in Emotional Narratives about Failed Romantic Relationships and Subsequent Mental Health. Journal of Language and Social Psychology 24, 252-268, doi:10.1177/0261927x05278386 (2005).

29 Kross, E. \& Ayduk, O. Facilitating Adaptive Emotional Analysis: Distinguishing DistancedAnalysis of Depressive Experiences From Immersed-Analysis and Distraction. Personality and Social Psychology Bulletin 34, 924-938, doi:10.1177/0146167208315938 (2008).

30 Heim, C. \& Nemeroff, C. B. The role of childhood trauma in the neurobiology of mood and anxiety disorders: preclinical and clinical studies. Biol Psychiatry 49, 1023-1039 (2001).

31 Charney, D. S. Psychobiological mechanisms of resilience and vulnerability: implications for successful adaptation to extreme stress. Am J Psychiatry 161, 195-216, doi:10.1176/appi.ajp.161.2.195 (2004). 
32 Yehuda, R., Brand, S. \& Yang, R. K. Plasma neuropeptide Y concentrations in combat exposed veterans: relationship to trauma exposure, recovery from PTSD, and coping. Biol Psychiatry 59, 660-663, doi:10.1016/j.biopsych.2005.08.027 (2006).

33 Sajdyk, T. J., Shekhar, A. \& Gehlert, D. R. Interactions between NPY and CRF in the amygdala to regulate emotionality. Neuropeptides 38, 225-234, doi:10.1016/j.npep.2004.05.006 (2004).

34 Gutman, A. R., Yang, Y., Ressler, K. J. \& Davis, M. The role of neuropeptide $Y$ in the expression and extinction of fear-potentiated startle. J Neurosci 28, 12682-12690, doi:10.1523/jneurosci.2305-08.2008 (2008).

35 Sajdyk, T. J. et al. Neuropeptide $Y$ in the amygdala induces long-term resilience to stressinduced reductions in social responses but not hypothalamic-adrenal-pituitary axis activity or hyperthermia. J Neurosci 28, 893-903, doi:10.1523/jneurosci.0659-07.2008 (2008).

36 Duman, R. S. \& Monteggia, L. M. A neurotrophic model for stress-related mood disorders. Biol Psychiatry 59, 1116-1127, doi:10.1016/j.biopsych.2006.02.013 (2006).

37 Eisch, A. J. et al. Brain-derived neurotrophic factor in the ventral midbrain-nucleus accumbens pathway: a role in depression. Biol Psychiatry 54, 994-1005 (2003).

38 Griffiths, B. B. \& Hunter, R. G. Neuroepigenetics of stress. Neuroscience 275, 420-435, doi:https://doi.org/10.1016/j.neuroscience.2014.06.041 (2014).

39 I-Motif DNA Structures May Regulate Promoters and Telomeres. Cancer Discov 8, 674, doi:10.1158/2159-8290.CD-RW2018-077 (2018).

40 Reilly, M. T., Faulkner, G. J., Dubnau, J., Ponomarev, I. \& Gage, F. H. The role of transposable elements in health and diseases of the central nervous system. The Journal of neuroscience : the official journal of the Society for Neuroscience 33, 17577-17586, doi:10.1523/JNEUROSCI.3369-13.2013 (2013).

41 Hunter, R. Stress, Transposons, and the Brain Epigenome. (2016).

42 Abou Assi, H., Garavis, M., Gonzalez, C. \& Damha, M. J. i-Motif DNA: structural features and significance to cell biology. Nucleic Acids Res 46, 8038-8056, doi:10.1093/nar/gky735 (2018).

43 Hunter, R. G., Gagnidze, K., McEwen, B. S. \& Pfaff, D. W. Stress and the dynamic genome: Steroids, epigenetics, and the transposome. Proc Natl Acad Sci U S A 112, 6828-6833, doi:10.1073/pnas.1411260111 (2015).

44 Hunter, R. G., McEwen, B. S. \& Pfaff, D. W. Environmental stress and transposon transcription in the mammalian brain. Mob Genet Elements 3, e24555, doi:10.4161/mge.24555 (2013).

45 Sara, S. J. The locus coeruleus and noradrenergic modulation of cognition. Nat Rev Neurosci 10, 211-223, doi:10.1038/nrn2573 (2009).

46 Berridge, C. W. \& Waterhouse, B. D. The locus coeruleus-noradrenergic system: modulation of behavioral state and state-dependent cognitive processes. Brain Res Brain Res Rev 42, 33-84 (2003).

47 Katsuki, H., Izumi, Y. \& Zorumski, C. F. Noradrenergic regulation of synaptic plasticity in the hippocampal CA1 region. J Neurophysiol 77, 3013-3020, doi:10.1152/jn.1997.77.6.3013 (1997). 
48 O'Dell, T. J., Connor, S. A., Guglietta, R. \& Nguyen, P. V. beta-Adrenergic receptor signaling and modulation of long-term potentiation in the mammalian hippocampus. Learn Mem 22, 461-471, doi:10.1101/Im.031088.113 (2015).

$49 \mathrm{Hu}, \mathrm{H}$. et al. Emotion Enhances Learning via Norepinephrine Regulation of AMPAReceptor Trafficking. Cell 131, 160-173, doi:https://doi.org/10.1016/j.cell.2007.09.017 (2007).

50 Tully, K. \& Bolshakov, V. Y. Emotional enhancement of memory: how norepinephrine enables synaptic plasticity. Molecular Brain 3, 15, doi:10.1186/1756-6606-3-15 (2010).

51 Lazzaro, S. C., Hou, M., Cunha, C., LeDoux, J. E. \& Cain, C. K. Antagonism of lateral amygdala alpha1-adrenergic receptors facilitates fear conditioning and long-term potentiation. Learning \& Memory 17, 489-493, doi:10.1101/Im.1918210 (2010).

52 Schwarz, L. A. \& Luo, L. Organization of the locus coeruleus-norepinephrine system. Curr Biol 25, R1051-R1056, doi:10.1016/j.cub.2015.09.039 (2015).

53 Esler, M. et al. The neuronal noradrenaline transporter, anxiety and cardiovascular disease. J Psychopharmaco/ 20, 60-66, doi:10.1177/1359786806066055 (2006).

54 Johnson, L., Hou, M., Prager, E. \& LeDoux, J. Regulation of the Fear Network by Mediators of Stress: Norepinephrine Alters the Balance between Cortical and Subcortical Afferent Excitation of the Lateral Amygdala. Frontiers in Behavioral Neuroscience 5, doi:10.3389/fnbeh.2011.00023 (2011).

55 Charney, D. S. Neuroanatomical circuits modulating fear and anxiety behaviors. Acta Psychiatr Scand Suppl, 38-50 (2003).

56 McGaugh, J. L. The amygdala modulates the consolidation of memories of emotionally arousing experiences. Annu Rev Neurosci 27, 1-28, doi:10.1146/annurev.neuro.27.070203.144157 (2004).

57 Klann, E., Antion, M. D., Banko, J. L. \& Hou, L. Synaptic plasticity and translation initiation. Learn Mem 11, 365-372, doi:10.1101/Im.79004 (2004).

58 Gelinas, J. N. et al. ERK and mTOR signaling couple beta-adrenergic receptors to translation initiation machinery to gate induction of protein synthesis-dependent longterm potentiation. J Biol Chem 282, 27527-27535, doi:10.1074/jbc.M701077200 (2007).

59 Jarome, T. J., Perez, G. A., Hauser, R. M., Hatch, K. M. \& Lubin, F. D. EZH2 Methyltransferase Activity Controls Pten Expression and mTOR Signaling during Fear Memory Reconsolidation. J Neurosci 38, 7635-7648, doi:10.1523/JNEUROSCI.053818.2018 (2018).

60 Takei, N. \& Nawa, H. mTOR signaling and its roles in normal and abnormal brain development. Frontiers in Molecular Neuroscience 7, doi:10.3389/fnmol.2014.00028 (2014).

61 Hoeffer, C. A. \& Klann, E. mTOR signaling: at the crossroads of plasticity, memory and disease. Trends in neurosciences 33, 67-75, doi:10.1016/j.tins.2009.11.003 (2010).

62 Graber, T. E., McCamphill, P. K. \& Sossin, W. S. A recollection of mTOR signaling in learning and memory. Learn Mem 20, 518-530, doi:10.1101/Im.027664.112 (2013).

63 Mac Callum, P. E., Hebert, M., Adamec, R. E. \& Blundell, J. Systemic inhibition of mTOR kinase via rapamycin disrupts consolidation and reconsolidation of auditory fear memory. Neurobiol Learn Mem 112, 176-185, doi:10.1016/j.nIm.2013.08.014 (2014). 
64 Bliss, T. V. \& Gardner-Medwin, A. R. Long-lasting potentiation of synaptic transmission in the dentate area of the unanaestetized rabbit following stimulation of the perforant path. J Physiol 232, 357-374 (1973).

65 Bliss, T. V. \& Collingridge, G. L. A synaptic model of memory: long-term potentiation in the hippocampus. Nature 361, 31-39, doi:10.1038/361031a0 (1993).

66 Bear, M. F. \& Malenka, R. C. Synaptic plasticity: LTP and LTD. Curr Opin Neurobiol 4, 389399 (1994).

67 Kandel, E. R. The molecular biology of memory storage: a dialog between genes and synapses. Biosci Rep 21, 565-611 (2001).

68 Maity, S., Jarome, T. J., Blair, J., Lubin, F. D. \& Nguyen, P. V. Noradrenaline goes nuclear: epigenetic modifications during long-lasting synaptic potentiation triggered by activation of beta-adrenergic receptors. J Physiol 594, 863-881, doi:10.1113/jp271432 (2016).

69 Ferry, B., Magistretti, P. J. \& Pralong, E. Noradrenaline modulates glutamate-mediated neurotransmission in the rat basolateral amygdala in vitro. Eur J Neurosci 9, 1356-1364 (1997).

70 Huang, Y. Y., Martin, K. C. \& Kandel, E. R. Both protein kinase A and mitogen-activated protein kinase are required in the amygdala for the macromolecular synthesisdependent late phase of long-term potentiation. J Neurosci 20, 6317-6325 (2000).

71 DeBock, F. et al. Alpha2-adrenoreceptor activation inhibits LTP and LTD in the basolateral amygdala: involvement of Gi/o-protein-mediated modulation of Ca2+channels and inwardly rectifying K+-channels in LTD. Eur J Neurosci 17, 1411-1424 (2003).

72 Braga, M. F., Aroniadou-Anderjaska, V., Manion, S. T., Hough, C. J. \& Li, H. Stress impairs alpha(1A) adrenoceptor-mediated noradrenergic facilitation of GABAergic transmission in the basolateral amygdala. Neuropsychopharmacology 29, 45-58, doi:10.1038/sj.npp.1300297 (2004).

73 Shepherd-Banigan, M. E. et al. in Interventions to Support Caregivers or Families of Patients with TBI, PTSD, or Polytrauma: A Systematic Review VA Evidence-based Synthesis Program Reports (2018).

74 Rubin, D. C. The coherence of memories for trauma: evidence from posttraumatic stress disorder. Conscious Cogn 20, 857-865, doi:10.1016/j.concog.2010.03.018 (2011).

75 O'Kearney, R. \& Perrott, K. Trauma narratives in posttraumatic stress disorder: a review. J Trauma Stress 19, 81-93, doi:10.1002/jts.20099 (2006).

76 Jaeger, J., Lindblom, K. M., Parker-Guilbert, K. \& Zoellner, L. A. Trauma Narratives: It's What You Say, Not How You Say It. Psychol Trauma 6, 473-481, doi:10.1037/a0035239 (2014).

77 Bucci, W. \& Freedman, N. The language of depression. Bulletin of the Menninger Clinic 45, 334-358 (1981).

78 Booker, J. A. et al. Narratives in the Immediate Aftermath of Traumatic Injury: Markers of Ongoing Depressive and Posttraumatic Stress Disorder Symptoms. J Trauma Stress 31, 273-285, doi:10.1002/jts.22271 (2018).

79 Chebib, M. \& Johnston, G. A. The 'ABC' of GABA receptors: a brief review. Clin Exp Pharmacol Physiol 26, 937-940 (1999). 
80 Bormann, J. \& Feigenspan, A. GABAC receptors. Trends in neurosciences 18, 515-519 (1995).

81 Pennebaker, J. W. \& Stone, L. D. Words of wisdom: language use over the life span. J Pers Soc Psychol 85, 291-301 (2003).

82 Mehl, M. R. \& Pennebaker, J. W. The sounds of social life: a psychometric analysis of students' daily social environments and natural conversations. J Pers Soc Psychol 84, 857-870 (2003).

83 Hirsh, J. B., Deyoung, C. G. \& Peterson, J. B. Metatraits of the Big Five differentially predict engagement and restraint of behavior. J Pers 77, 1085-1102, doi:10.1111/j.14676494.2009.00575.x (2009).

84 Pennebaker, J. W. Putting Stress into Words - Health, Linguistic, and Therapeutic Implications. Behaviour Research and Therapy 31, 539-548, doi:Doi 10.1016/00057967(93)90105-4 (1993).

85 Campbell, R. S. \& Pennebaker, J. W. The secret life of pronouns: flexibility in writing style and physical health. Psychol Sci 14, 60-65, doi:10.1111/1467-9280.01419 (2003).

86 Mathews, C. O. A review of behavioral theories of depression and a self-regulation model for depression. Psychotherapy: Theory, Research \& Practice 14, 79-86, doi:10.1037/h0087496 (1977).

87 Flory, J. D. \& Yehuda, R. Comorbidity between post-traumatic stress disorder and major depressive disorder: alternative explanations and treatment considerations. Dialogues Clin Neurosci 17, 141-150 (2015).

88 Weisskopf, M. G. \& LeDoux, J. E. Distinct populations of NMDA receptors at subcortical and cortical inputs to principal cells of the lateral amygdala. J Neurophysiol 81, 930-934, doi:10.1152/jn.1999.81.2.930 (1999).

89 Diaz-Mataix, L. et al. Characterization of the amplificatory effect of norepinephrine in the acquisition of Pavlovian threat associations. Learn Mem 24, 432-439, doi:10.1101/Im.044412.116 (2017).

90 Cain, C. K., Blouin, A. M. \& Barad, M. Adrenergic transmission facilitates extinction of conditional fear in mice. Learn Mem 11, 179-187, doi:10.1101/Im.71504 (2004).

91 Izquierdo, I., Cammarota, M., Vianna, M. M. \& Bevilaqua, L. R. The inhibition of acquired fear. Neurotox Res 6, 175-188 (2004).

92 Aston-Jones, G., Delfs, J. M., Druhan, J. \& Zhu, Y. The bed nucleus of the stria terminalis. A target site for noradrenergic actions in opiate withdrawal. Ann N Y Acad Sci 877, 486498 (1999).

93 Aston-Jones, G., Rajkowski, J. \& Cohen, J. Role of locus coeruleus in attention and behavioral flexibility. Biol Psychiatry 46, 1309-1320 (1999).

94 Aston-Jones, G. \& Cohen, J. D. Adaptive gain and the role of the locus coeruleusnorepinephrine system in optimal performance. J Comp Neurol 493, 99-110, doi:10.1002/cne.20723 (2005).

95 Nieuwenhuis, S., Aston-Jones, G. \& Cohen, J. D. Decision making, the P3, and the locus coeruleus-norepinephrine system. Psychol Bull 131, 510-532, doi:10.1037/00332909.131.4.510 (2005). 
96 Aston-Jones, G. \& Cohen, J. D. An integrative theory of locus coeruleus-norepinephrine function: adaptive gain and optimal performance. Annu Rev Neurosci 28, 403-450, doi:10.1146/annurev.neuro.28.061604.135709 (2005).

97 Razzoli, M., McCallum, J., Gurney, A., Engeland, W. C. \& Bartolomucci, A. Chronic stress aggravates glucose intolerance in leptin receptor-deficient (db/db) mice. Genes Nutr 10, 458, doi:10.1007/s12263-015-0458-2 (2015).

98 McCall, J. G. et al. CRH Engagement of the Locus Coeruleus Noradrenergic System Mediates Stress-Induced Anxiety. Neuron 87, 605-620, doi:10.1016/j.neuron.2015.07.002 (2015).

99 Prouty, E. W., Waterhouse, B. D. \& Chandler, D. J. Corticotropin releasing factor dosedependently modulates excitatory synaptic transmission in the noradrenergic nucleus locus coeruleus. Eur J Neurosci 45, 712-722, doi:10.1111/ejn.13501 (2017).

100 Prouty, E. W., Chandler, D. J. \& Waterhouse, B. D. Neurochemical differences between target-specific populations of rat dorsal raphe projection neurons. Brain Res 1675, 2840, doi:10.1016/j.brainres.2017.08.031 (2017).

101 Chandler, D. J., Gao, W. J. \& Waterhouse, B. D. Heterogeneous organization of the locus coeruleus projections to prefrontal and motor cortices. Proc Natl Acad Sci U S A 111, 6816-6821, doi:10.1073/pnas.1320827111 (2014).

102 Chandler, D. J. Evidence for a specialized role of the locus coeruleus noradrenergic system in cortical circuitries and behavioral operations. Brain Res 1641, 197-206, doi:10.1016/j.brainres.2015.11.022 (2016).

103 Chen, M. J., Nguyen, T. V., Pike, C. J. \& Russo-Neustadt, A. A. Norepinephrine induces BDNF and activates the PI-3K and MAPK cascades in embryonic hippocampal neurons. Cell Signal 19, 114-128, doi:10.1016/j.cellsig.2006.05.028 (2007).

104 Chen, M. \& Russo-Neustadt, A. Norepinephrine Induces BDNF and Activates CREB and Discriminates among Protein Kinase $\mathrm{C}$ Isoforms in Cultured Embryonic Hippocampal Neurons. Neuroscience and Medicine Vol.08No.04, 15, doi:10.4236/nm.2017.84008 (2017).

105 Milner, T. A., Shah, P. \& Pierce, J. P. beta-adrenergic receptors primarily are located on the dendrites of granule cells and interneurons but also are found on astrocytes and a few presynaptic profiles in the rat dentate gyrus. Synapse 36, 178-193, doi:10.1002/(SICI)1098-2396(20000601)36:3<178::AID-SYN3>3.0.CO;2-6 (2000).

106 Caetano, M. S. et al. Noradrenergic control of error perseveration in medial prefrontal cortex. Front Integr Neurosci 6, 125, doi:10.3389/fnint.2012.00125 (2012).

107 Arnsten, A. F., Raskind, M. A., Taylor, F. B. \& Connor, D. F. The Effects of Stress Exposure on Prefrontal Cortex: Translating Basic Research into Successful Treatments for PostTraumatic Stress Disorder. Neurobiol Stress 1, 89-99, doi:10.1016/j.ynstr.2014.10.002 (2015).

108 Hains, A. B., Yabe, Y. \& Arnsten, A. F. Chronic Stimulation of Alpha-2A-Adrenoceptors With Guanfacine Protects Rodent Prefrontal Cortex Dendritic Spines and Cognition From the Effects of Chronic Stress. Neurobiol Stress 2, 1-9, doi:10.1016/j.ynstr.2015.01.001 (2015).

109 Ramos, J. C. Studies on the mechanisms of learning. IV. Ontogeny of calcium channels in the rat's cortex. Acta Physiol Lat Am 25, 288-298 (1975). 
110 Ramos, J. M. J. Perirhinal cortex involvement in allocentric spatial learning in the rat: Evidence from doubly marked tasks. Hippocampus 27, 507-517, doi:10.1002/hipo.22707 (2017).

111 Wang, M. et al. Alpha2A-adrenoceptors strengthen working memory networks by inhibiting CAMP-HCN channel signaling in prefrontal cortex. Cell 129, 397-410, doi:10.1016/j.cell.2007.03.015 (2007).

112 Ramos, B. P. \& Arnsten, A. F. Adrenergic pharmacology and cognition: focus on the prefrontal cortex. Pharmacol Ther 113, 523-536, doi:10.1016/j.pharmthera.2006.11.006 (2007).

113 Giustino, T. F. \& Maren, S. Noradrenergic Modulation of Fear Conditioning and Extinction. Front Behav Neurosci 12, 43, doi:10.3389/fnbeh.2018.00043 (2018).

114 Lim, E. P., Dawe, G. S. \& Jay, T. M. Activation of beta- and alpha-2-adrenoceptors in the basolateral amygdala has opposing effects on hippocampal-prefrontal long-term potentiation. Neurobiol Learn Mem 137, 163-170, doi:10.1016/j.nlm.2016.11.020 (2017).

115 Gazarini, L., Stern, C. A., Piornedo, R. R., Takahashi, R. N. \& Bertoglio, L. J. PTSD-like memory generated through enhanced noradrenergic activity is mitigated by a dual step pharmacological intervention targeting its reconsolidation. Int J Neuropsychopharmacol 18, doi:10.1093/ijnp/pyu026 (2014).

116 Gazarini, L., Stern, C. A., Carobrez, A. P. \& Bertoglio, L. J. Enhanced noradrenergic activity potentiates fear memory consolidation and reconsolidation by differentially recruiting alpha1- and beta-adrenergic receptors. Learn Mem 20, 210-219, doi:10.1101/Im.030007.112 (2013).

117 Cain, C. K., Blouin, A. M. \& Barad, M. Temporally massed CS presentations generate more fear extinction than spaced presentations. J Exp Psychol Anim Behav Process 29, 323-333, doi:10.1037/0097-7403.29.4.323 (2003).

118 Auchter, A., Cormack, L. K., Niv, Y., Gonzalez-Lima, F. \& Monfils, M. H. ReconsolidationExtinction Interactions in Fear Memory Attenuation: The Role of Inter-Trial Interval Variability. Front Behav Neurosci 11, 2, doi:10.3389/fnbeh.2017.00002 (2017).

119 Auchter, A. M., Shumake, J., Gonzalez-Lima, F. \& Monfils, M. H. Preventing the return of fear using reconsolidation updating and methylene blue is differentially dependent on extinction learning. Sci Rep 7, 46071, doi:10.1038/srep46071 (2017).

120 Monfils, M. H. et al. Predicting extinction phenotype to optimize fear reduction. Psychopharmacology (Berl), doi:10.1007/s00213-018-5005-6 (2018).

121 Monfils, M. H., Cowansage, K. K., Klann, E. \& LeDoux, J. E. Extinction-reconsolidation boundaries: key to persistent attenuation of fear memories. Science 324, 951-955, doi:10.1126/science.1167975 (2009).

122 Schiller, D., Kanen, J. W., LeDoux, J. E., Monfils, M. H. \& Phelps, E. A. Extinction during reconsolidation of threat memory diminishes prefrontal cortex involvement. Proc Natl Acad Sci U S A 110, 20040-20045, doi:10.1073/pnas.1320322110 (2013).

123 Quirk, G. J. et al. Erasing fear memories with extinction training. J Neurosci 30, 1499314997, doi:10.1523/JNEUROSCI.4268-10.2010 (2010). 
124 Guan, J.-S., Xie, H. \& Ding, X. The role of epigenetic regulation in learning and memory. Experimental Neurology 268, 30-36, doi:https://doi.org/10.1016/j.expneurol.2014.05.006 (2015).

125 Daskalakis, N. P., Rijal, C. M., King, C., Huckins, L. M. \& Ressler, K. J. Recent Genetics and Epigenetics Approaches to PTSD. Curr Psychiatry Rep 20, 30, doi:10.1007/s11920-0180898-7 (2018).

126 Heindel, J. J., McAllister, K. A., Worth, L., Jr. \& Tyson, F. L. Environmental epigenomics, imprinting and disease susceptibility. Epigenetics 1, 1-6 (2006).

127 McClelland, S., Korosi, A., Cope, J., Ivy, A. \& Baram, T. Z. Emerging roles of epigenetic mechanisms in the enduring effects of early-life stress and experience on learning and memory. Neurobiology of Learning and Memory 96, 79-88, doi:https://doi.org/10.1016/j.nlm.2011.02.008 (2011).

128 Moore, L. D., Le, T. \& Fan, G. DNA methylation and its basic function. Neuropsychopharmacology 38, 23-38, doi:10.1038/npp.2012.112 (2013).

129 Bayles, R. et al. Epigenetic modification of the norepinephrine transporter gene in postural tachycardia syndrome. Arteriosclerosis, thrombosis, and vascular biology 32, 1910-1916, doi:10.1161/atvbaha.111.244343 (2012).

130 Coppersmith, G., Dredze, M. \& Harman, C. Quantifying Mental Health Signals in Twitter. Conference Proceedings (2014).

131 Coppersmith, G., Dredze, M., Harman, C. \& Hollingshead, K. From ADHD to SAD: Analyzing the Language of Mental Health on Twitter through Self-Reported Diagnoses. Conference Proceedings (2015).

132 Sap, M. et al. Developing Age and Gender Predictive Lexica over Social Media. Conference Proceedings (2014).

133 McNamee, P. M. Character N-Gram Tokenization for European Language Text Retrieval. J. Information Retrieval 7: 73 (2004).

134 Tausczik, Y. R. \& Pennebaker, J. W. The Psychological Meaning of Words: LIWC and Computerized Text Analysis Methods. Journal of Language and Social Psychology 29, 2454, doi:10.1177/0261927x09351676 (2010).

135 Badger, K., Royse, D. \& Moore, K. What's in a story? A text analysis of burn survivors' web-posted narratives. Soc Work Health Care 50, 577-594, doi:10.1080/00981389.2011.592114 (2011).

136 Rometsch-Ogioun El Sount, C. et al. Chronic pain in refugees with posttraumatic stress disorder (PTSD): A systematic review on patients' characteristics and specific interventions. J Psychosom Res, doi:10.1016/j.jpsychores.2018.07.014 (2018).

137 Mott, J. M., Galovski, T. E., Walsh, R. M. \& Elwood, L. S. Change in Trauma Narratives and Perceived Recall Ability over a Course of Cognitive Processing Therapy for PTSD. Traumatology (Tallahass Fla) 21, 47-54, doi:10.1037/trm0000012 (2015).

138 Knutsen, M. \& Jensen, T. K. Changes in the trauma narratives of youth receiving traumafocused cognitive behavioral therapy in relation to posttraumatic stress symptoms. Psychother Res, 1-13, doi:10.1080/10503307.2017.1303208 (2017).

139 Kenardy, J. et al. Dissociation in children's trauma narratives: an exploratory investigation. J Anxiety Disord 21, 456-466, doi:10.1016/j.janxdis.2006.05.007 (2007). 
140 Westerman, N. K., Cobham, V. E. \& McDermott, B. Trauma-Focused Cognitive Behavior Therapy: Narratives of Children and Adolescents. Qual Health Res 27, 226-235, doi:10.1177/1049732315627795 (2017).

141 Baddeley, J. L., Daniel, G. R. \& Pennebaker, J. W. How Henry Hellyer's use of language foretold his suicide. Crisis 32, 288-292, doi:10.1027/0227-5910/a000092 (2011).

142 Mowery, D. et al. Understanding Depressive Symptoms and Psychosocial Stressors on Twitter: A Corpus-Based Study. J Med Internet Res 19, e48, doi:10.2196/jmir.6895 (2017).

143 Weisskopf, M. G., Bauer, E. P. \& LeDoux, J. E. L-type voltage-gated calcium channels mediate NMDA-independent associative long-term potentiation at thalamic input synapses to the amygdala. J Neurosci 19, 10512-10519 (1999). 